\title{
Modeling and Prediction of Fan Noise
}

\author{
Ed Envia \\ M.S. 54-3, Acoustics Branch, NASA Glenn Research Center \\ Cleveland, Ohio 44212, U.S.A. \\ Edmane.envia-1@nasa.gov
}

Fan noise is a significant contributor to the total noise signature of a modern high bypass ratio aircraft engine and with the advent of ultra high bypass ratio engines like the geared turbofan, it is likely to remain so in the future. As such, accurate modeling and prediction of the basic characteristics of fan noise are necessary ingredients in designing quieter aircraft engines in order to ensure compliance with ever more stringent aviation noise regulations.

In this paper, results from a comprehensive study aimed at establishing the utility of current tools for modeling and predicting fan noise will be summarized. It should be emphasized that these tools exemplify present state of the practice and embody what is currently used at NASA and Industry for predicting fan noise. The ability of these tools to model and predict fan noise is assessed against a set of benchmark fan noise databases obtained for a range of representative fan cycles and operating conditions. Detailed comparisons between the predicted and measured narrowband spectral and directivity characteristics of fan nose will be presented in the full paper. General conclusions regarding the utility of current tools and recommendations for future improvements will also be given. 


\title{
Modeling and Prediction of Fan Noise
}

\author{
Ed Envia \\ NASA Glenn Research Center \\ Cleveland, Ohio, U.S.A.
}

Acoustics ‘ 08 Conference

Paris, France 


\section{Motivation}

$\square$ Fan noise is a significant contributor to the noise signature of a modern turbofan engine, especially for the emerging ultra high bypass cycle engines.

$\square$ Prediction and mitigation of fan noise depends on our ability to model accurately fan noise sources.

$\square$ Assess the utility of current modeling tools for predicting fan noise and identify areas of future research focus in fan noise modeling. 


\section{Approach}

$\square$ Select representative fan noise prediction codes and evaluate their predictive capabilities against a set of benchmark fan data.

$\square$ Carry out a comprehensive data-theory comparison to establish the level of fidelity of the codes. 


\section{Codes}

$\square$ Empirical

- Predict "farfield" fan noise spectra on third-octave basis.

- Model fan as a compact source.

$\square$ Analytical

- Predict narrowband spectra of in-duct fan noise.

- Typically, involve coupling quasi-2D unsteady aerodynamics with 3D duct acoustics. Idealized description of the blade row, base flow and incident turbulence.

$\square$ Computational (CAA)

- Predict induct/ farfield fan tone noise.

- 3D descriptions of the base flow, unsteady perturbations and blade-row geometry. 


\section{Code Input}

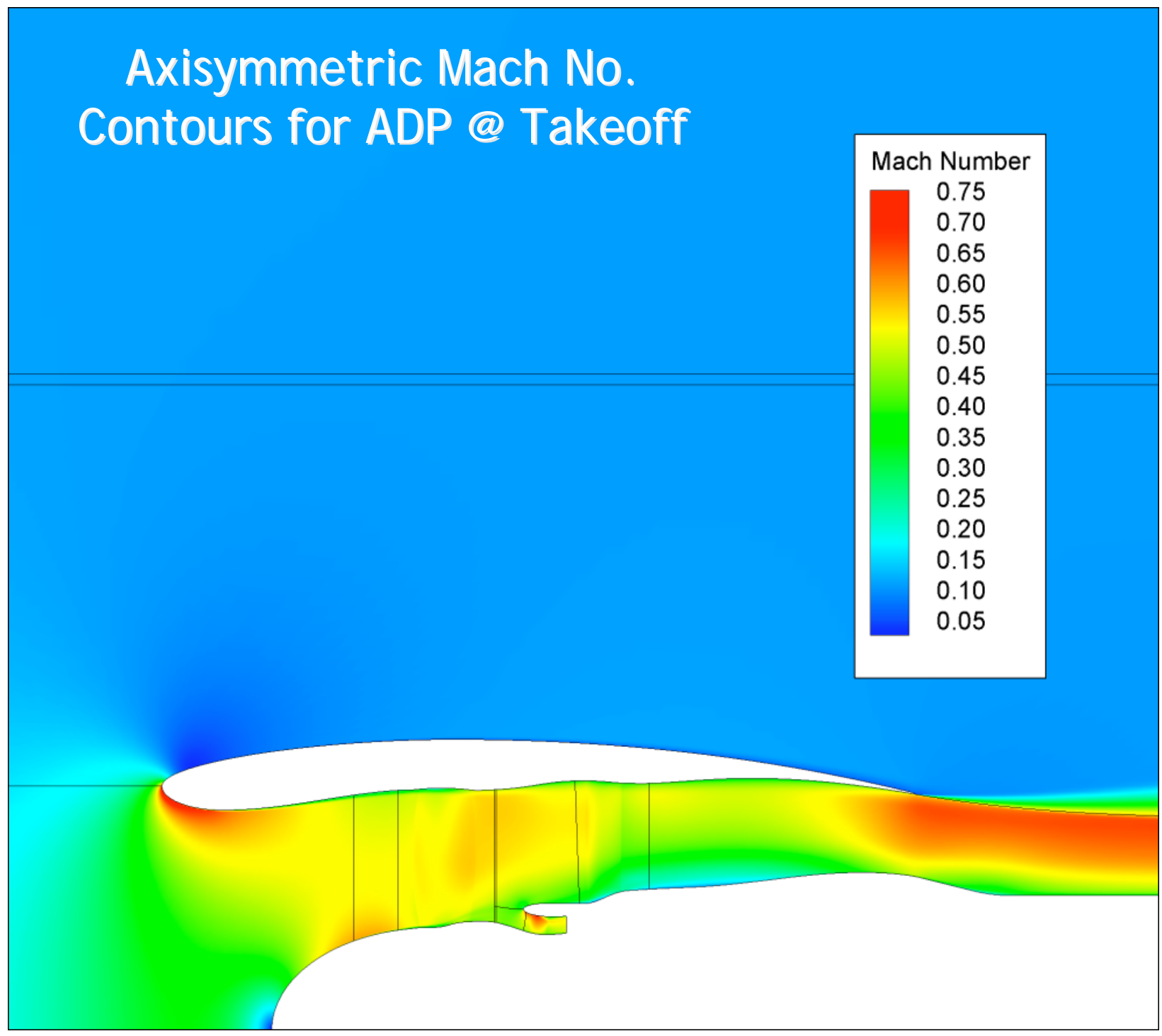




\section{Benchmark Fans}

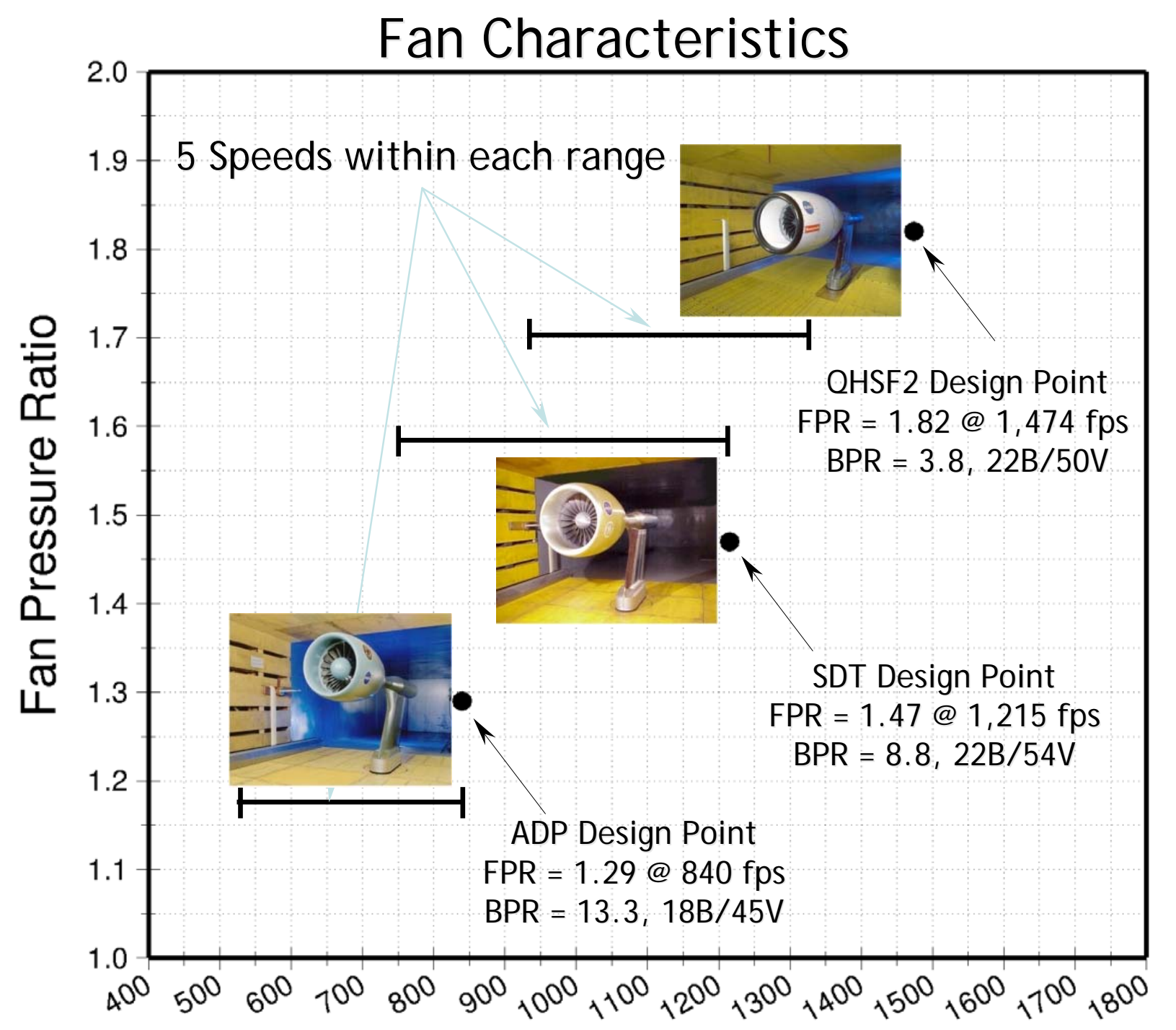




\section{Test Facility}

$\square$ 9' $\times 15^{\prime}$ Acoustic Wind Tunnel

- Sideline spectral measurements

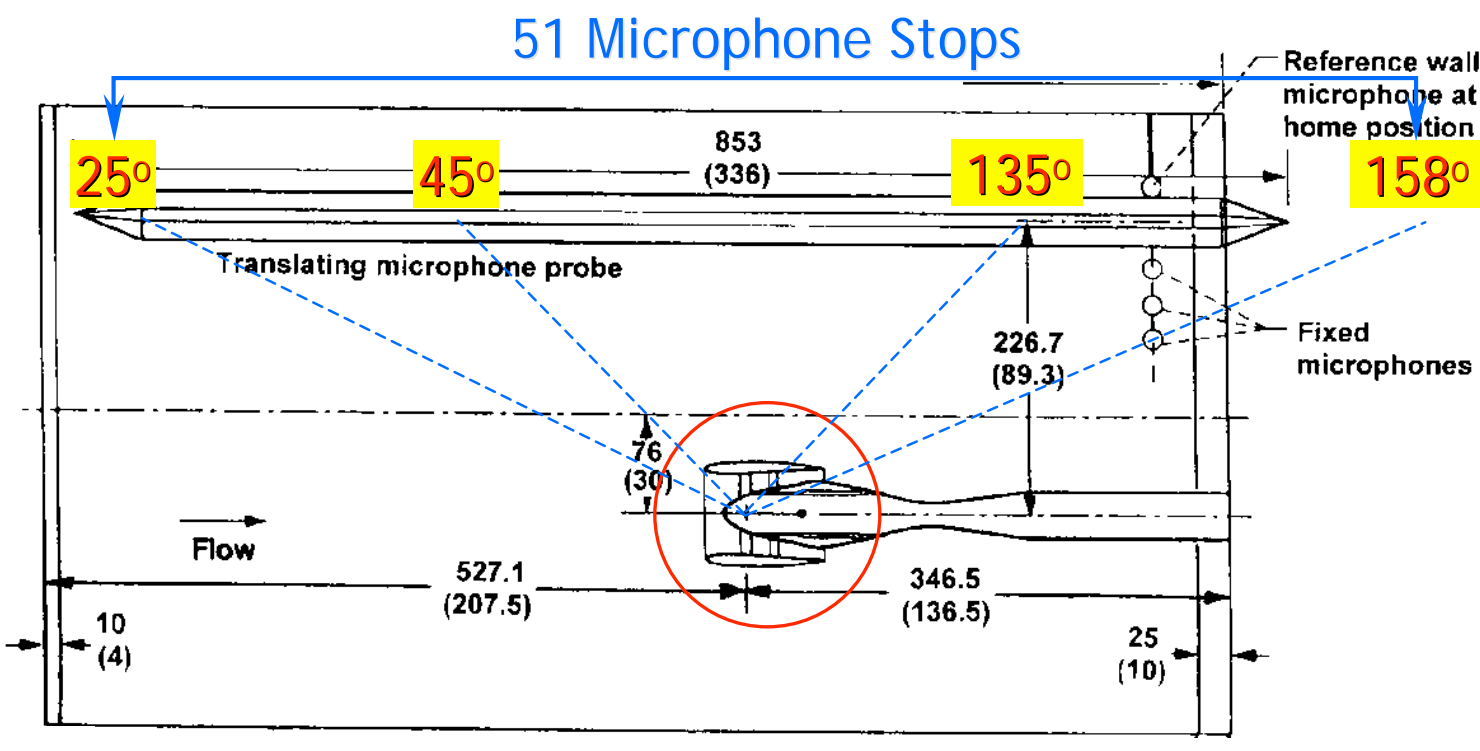

$\square$ Rotating Rake System

- In-duct tone/ mode measurements

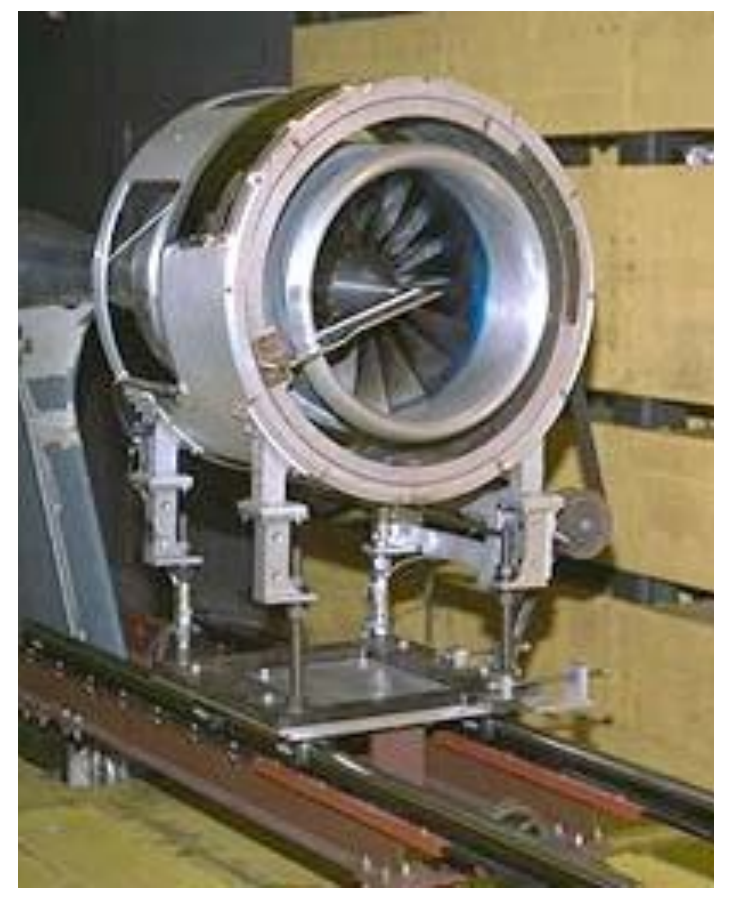




\section{Sample Results: Empirical Code}

ADP @Takeoff Condition

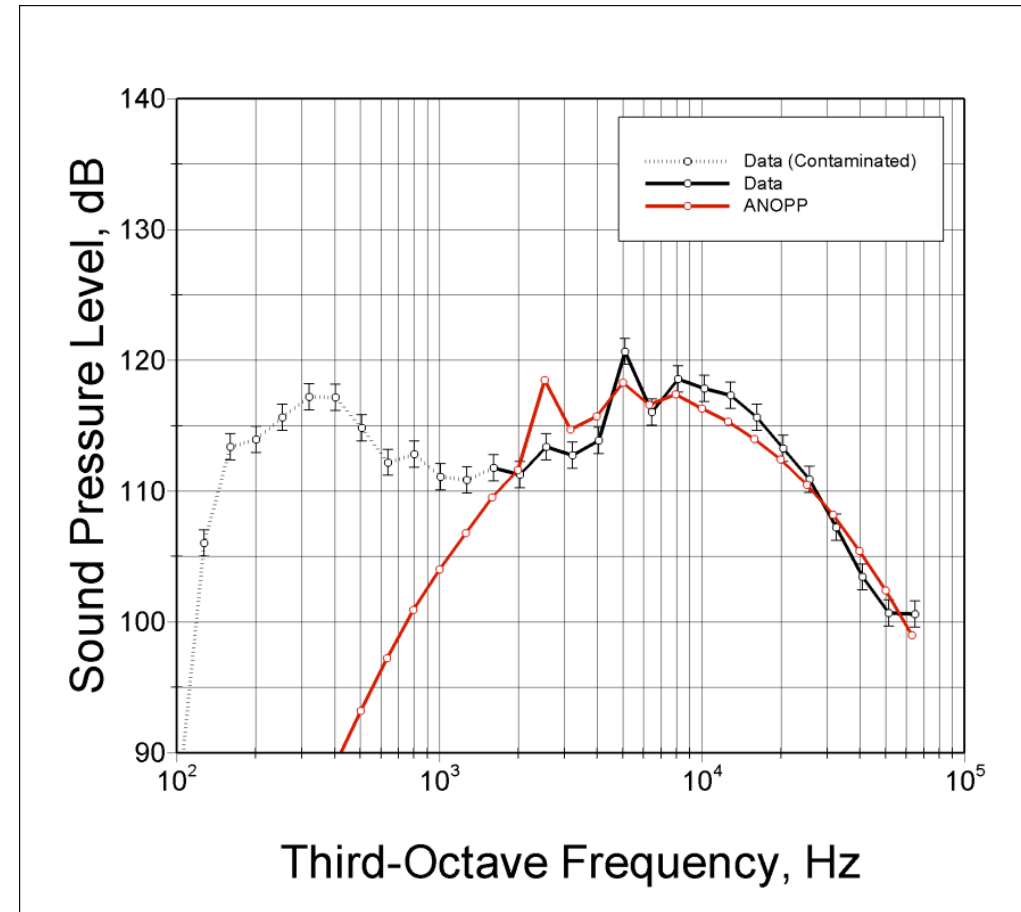

Inlet Microphone (45)

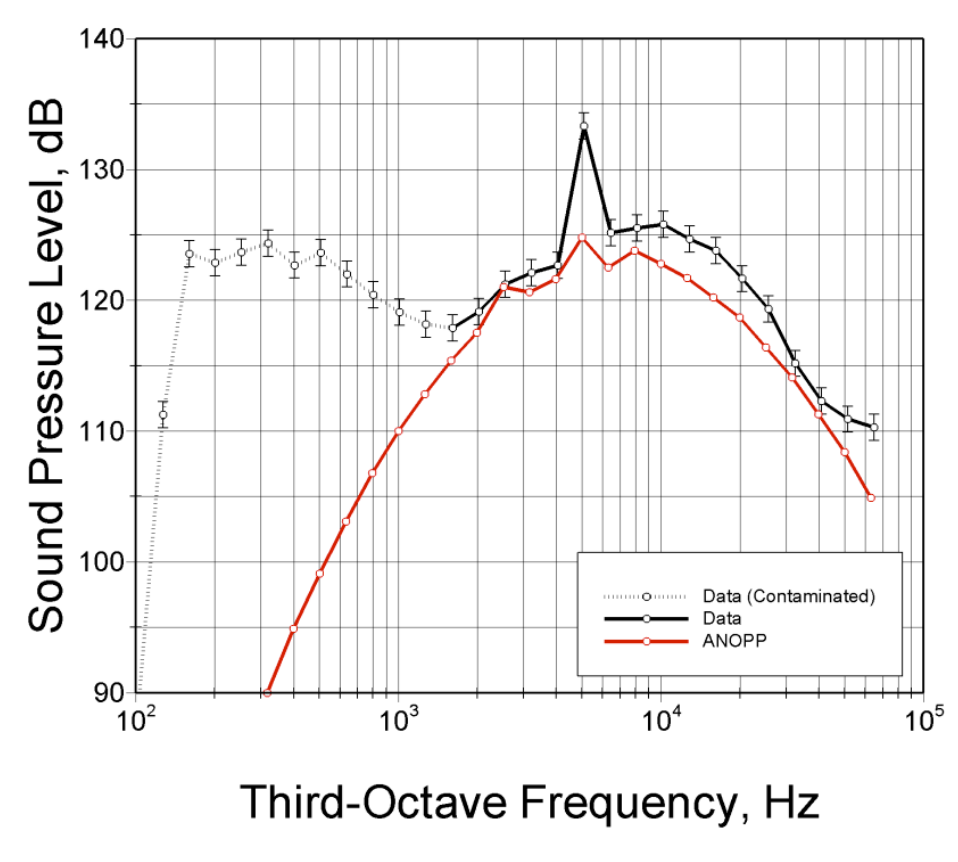

Exhaust Microphone (136) 


\section{Sample Results: Empirical Code}

SDT @Takeoff

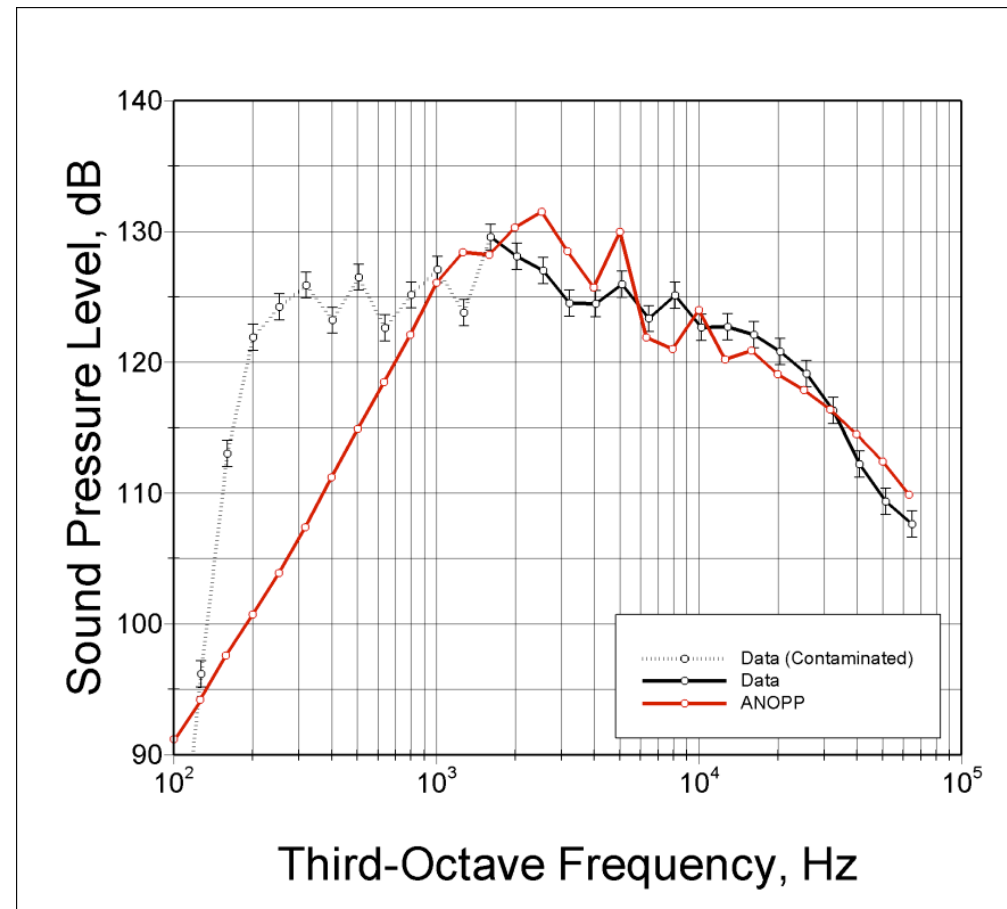

Inlet Microphone (45)
QHSF2 @Takeoff

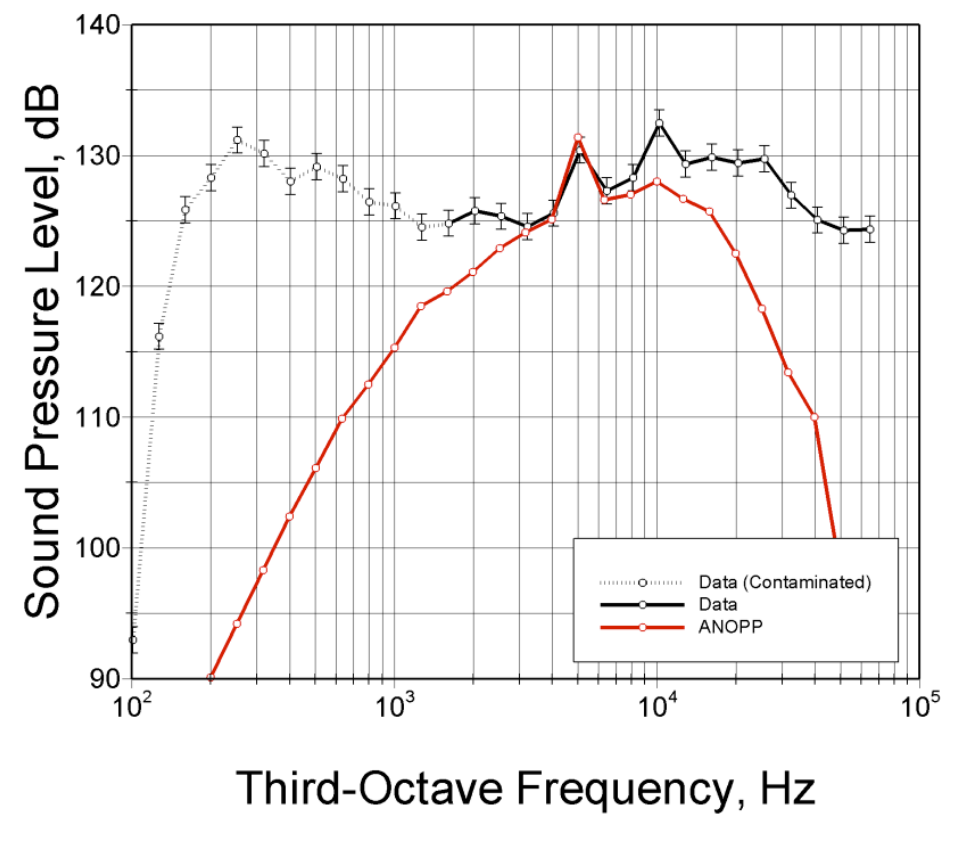

Exhaust Microphone (136) 


\section{Assessment}

\section{SDT @Takeoff}

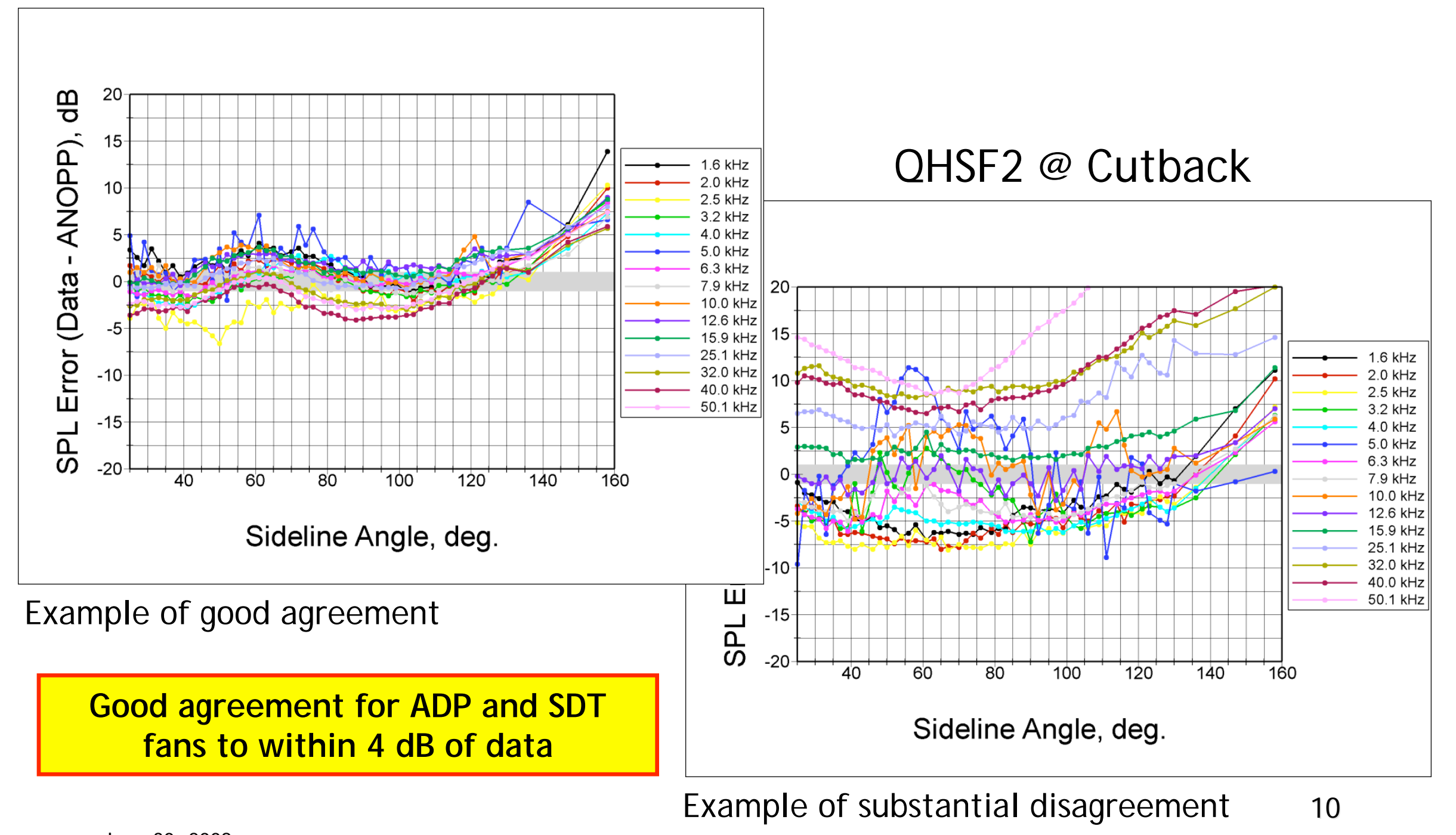




\section{Sample Results: Analytical Code}

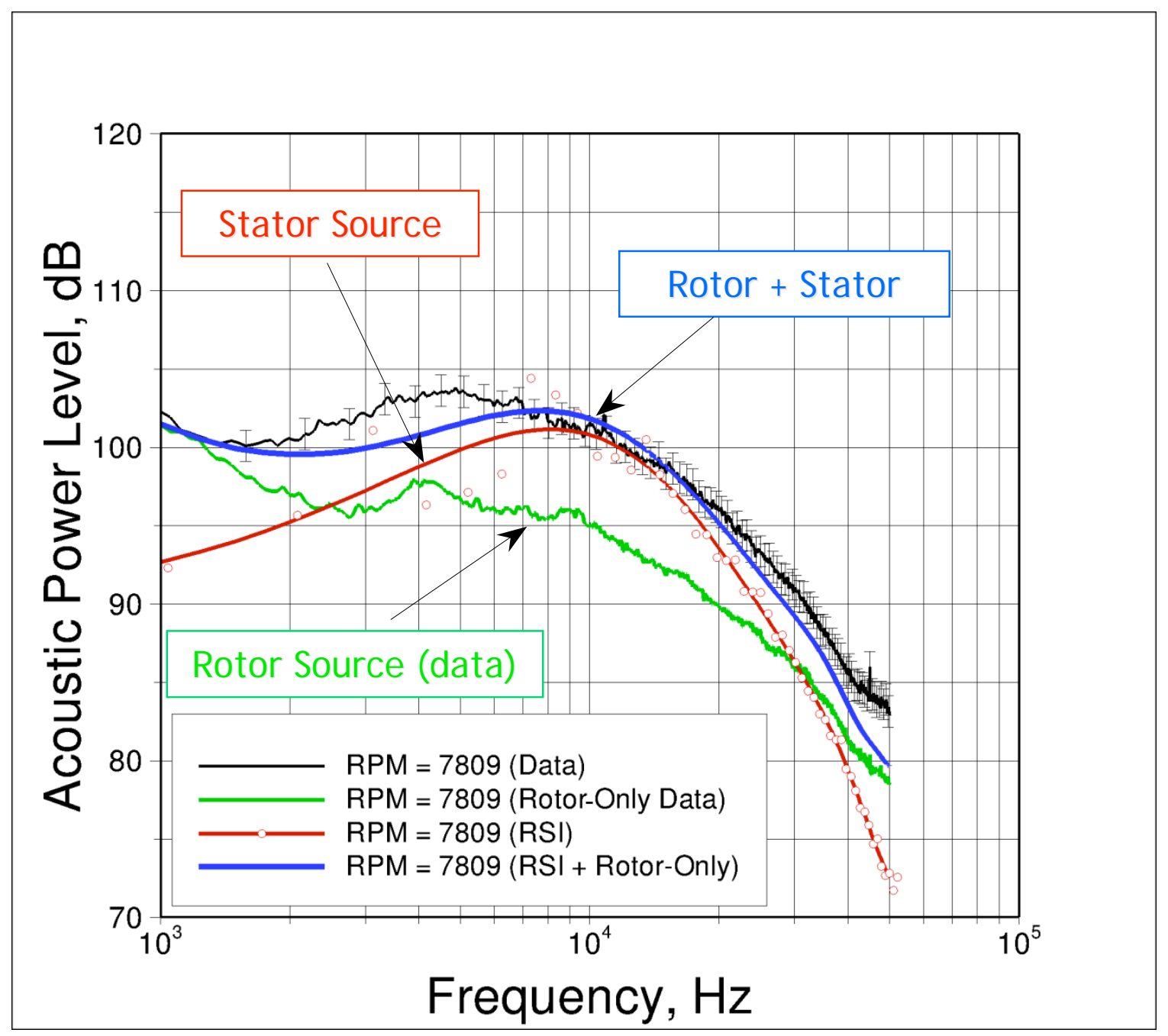




\section{Sample Results: Analytical Code}
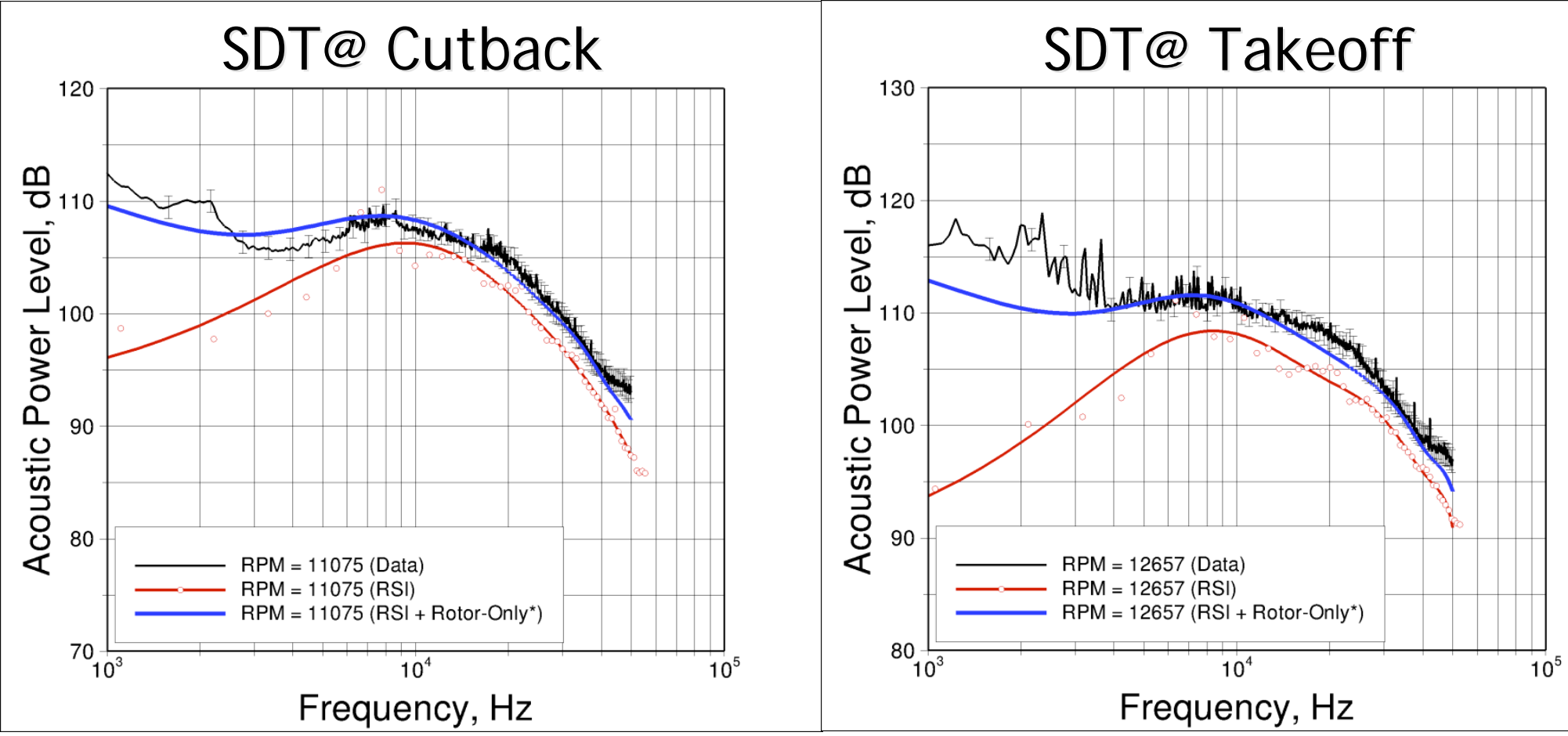

Favorable data-theory agreement when rotor sources are included 


\section{Assessment}

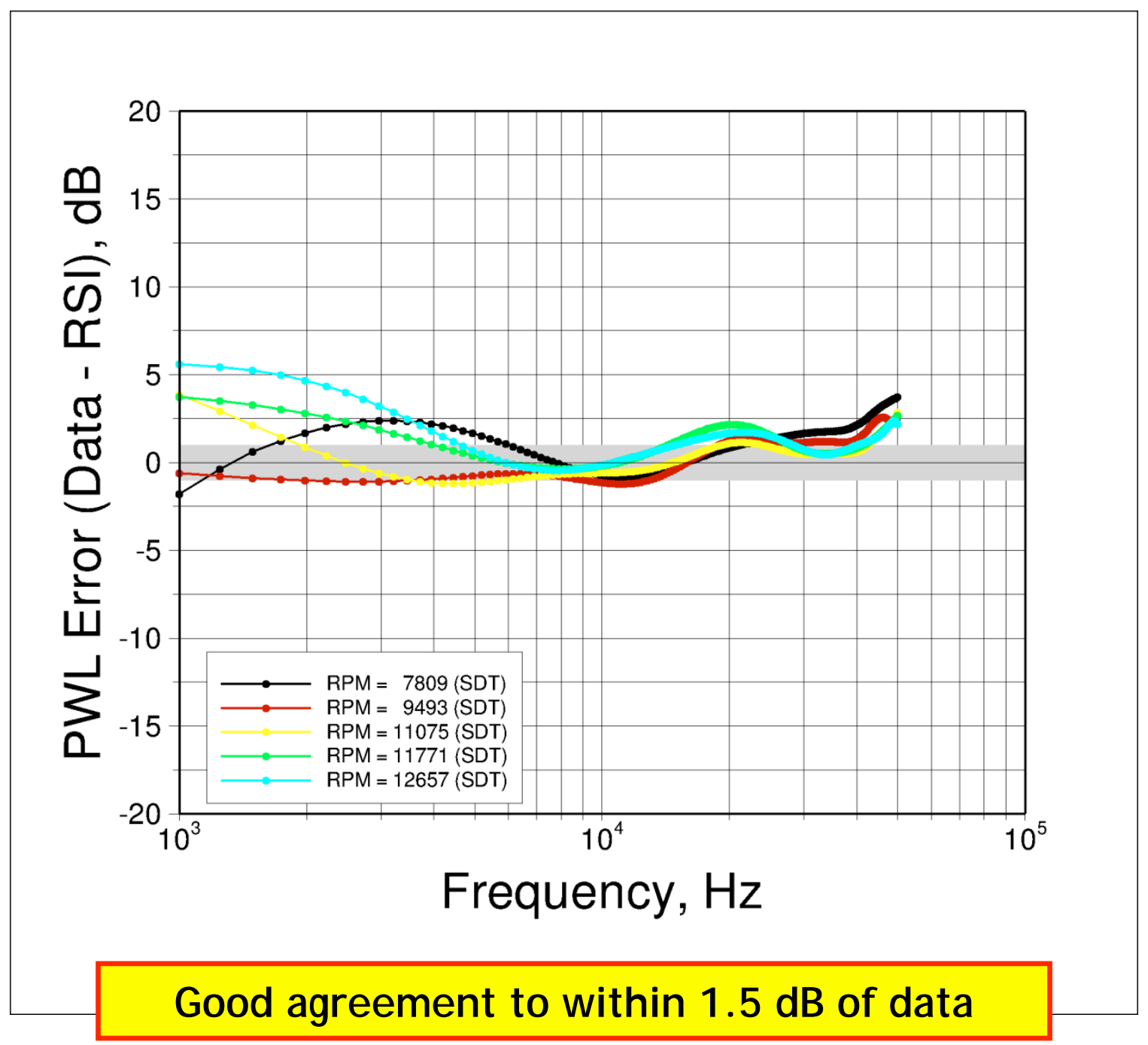




\section{Sample Results: CAA Code}

ADP @All Speeds

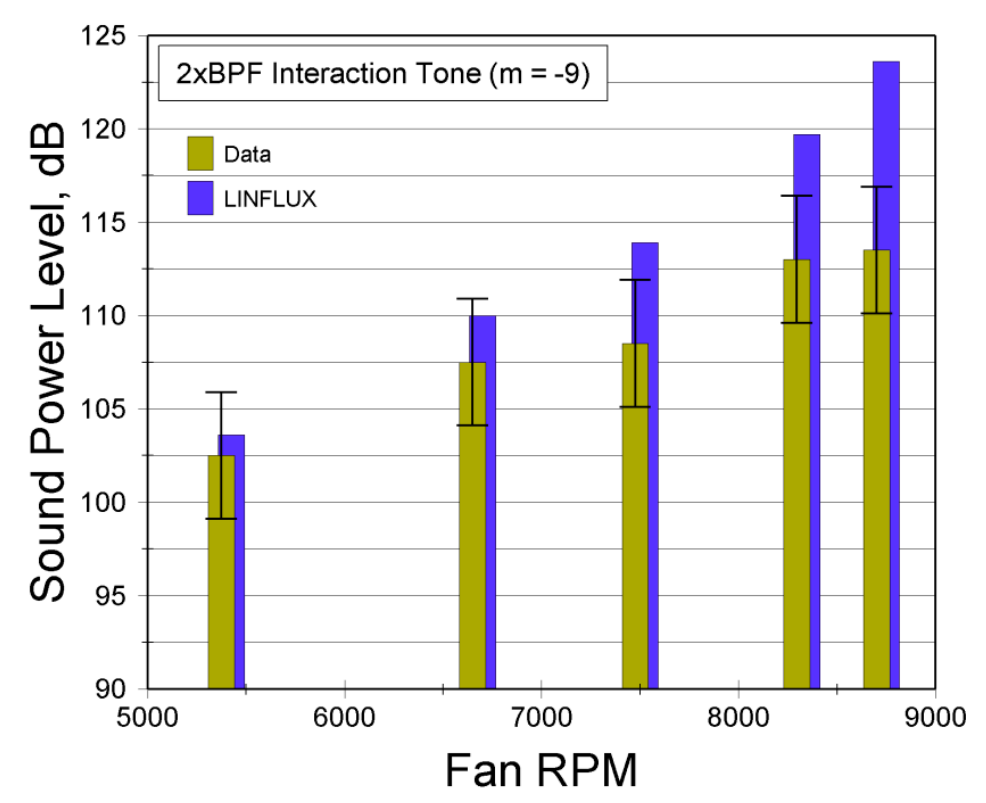

SDT@All Speeds

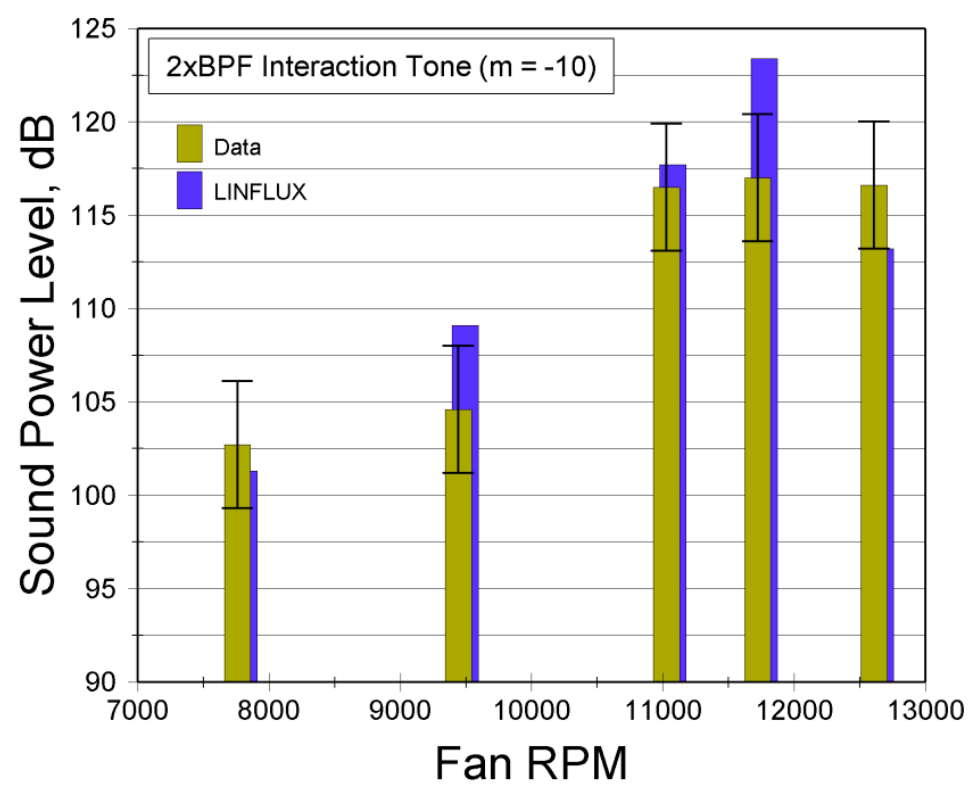

2xBPF Tone

QHSF2 solutions did not converge 


\section{Assessment}

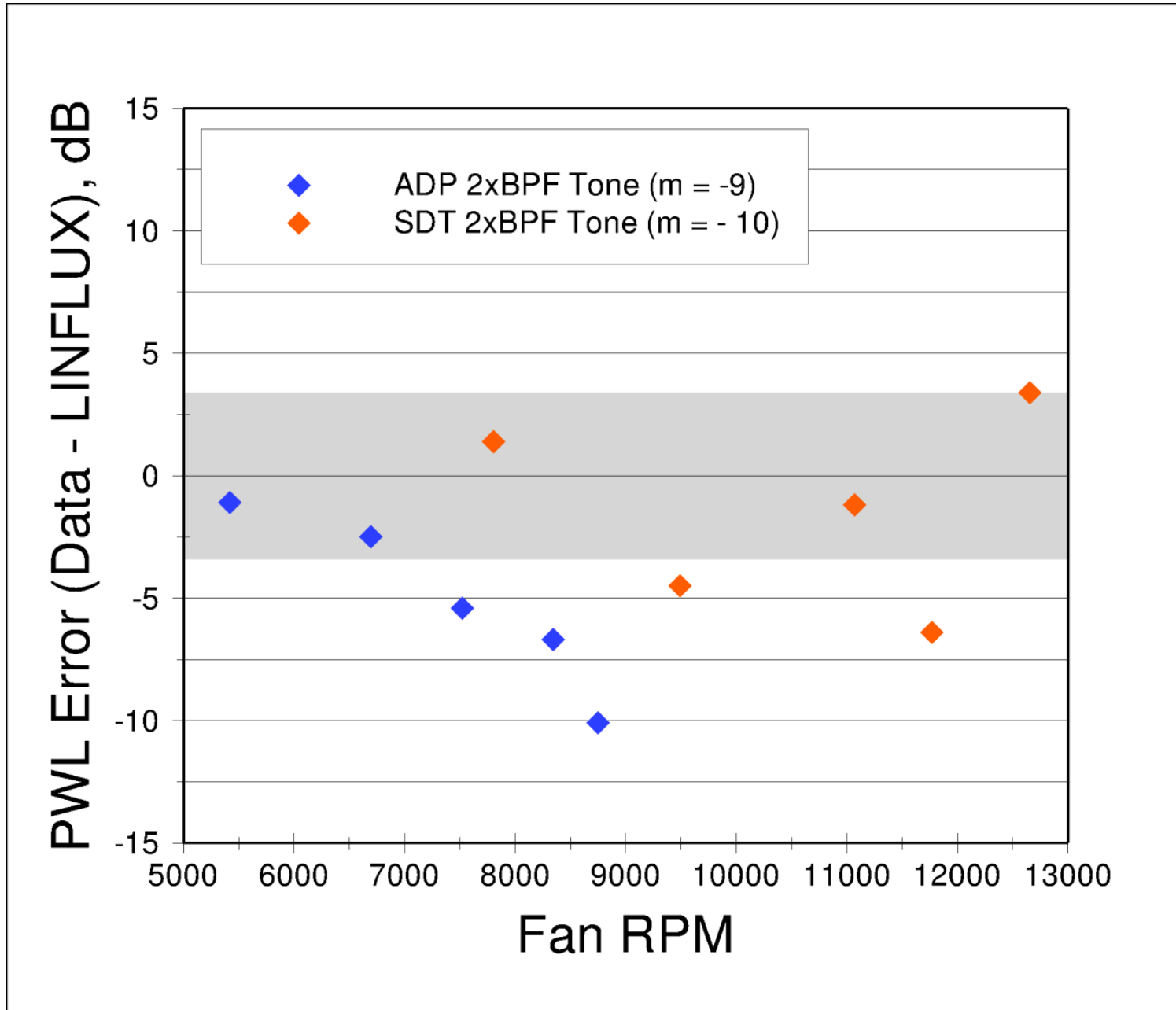

Good agreement to within uncertainty band of the data at low speeds, but large deviations at the higher speed in some cases 


\section{Summary}

$\square$ Completed first detailed assessment of NASA fan noise prediction codes and established the level of data-theory discrepancy for empirical, analytical and computational codes.

$\square$ For the most part, the data-theory discrepancy is within $4 \mathrm{~dB}$ or less.

$\square$ Modeling shortcomings and focus areas for future research have been identified. 